\title{
Studi Etnopedagogi Nilai-Nilai Sila Pancasila pada Budaya Lokal Masyarakat Adat Sumba
}

\author{
Heronimus Delu Pingge ${ }^{1_{\varpi}}$ \& Rahel Maga Aingu ${ }^{2}$
}

Program Studi PGSD, STKIP Weetebula, Indonesia

$\bowtie$ E-mail: pinggeroni@gmail.com

\begin{abstract}
Abstrak
Pancasila sebagai ideologi bangsa Indonesia dan kausa materialitas dari Pancasila adalah kebudayaan. Kebudayaan masyarakat adat Sumba merupakan kekayaan budaya Indonesia yang mendukung keutuhan Pancasila. Tulisan ini untuk menjawab beberapa pertanyaan penelitian sebagai berikut; Bagaimana refleksi nilai sila ketuhanan yang maha esa pada budaya lokal masyarakat adat Sumba?, 2) Bagaimana refleksi nilai sila kemanusiaan yang adil dan beradab pada budaya lokal masyarakat adat Sumba, 3) Bagaimana refleksi nilai persatuan Indonesia pada budaya lokal masyarakat adat Sumba, 4) Bagaimana refleksi nilai sila kerakyatan yang dipimpin oleh hikmat kebijaksanaan pada budaya lokal masyarakat adat Sumba, 5) Bagaimana refleksi nilai keadilan sosial bagi seluruh rakyat Indonesia pada budaya lokal masyarakat adat Sumba?. Perolehan data dilakukan dengan melakukan penelitian dengan metode fenomenologi, dalam metode tersebut data dikumpulkan melaui wawancara dan analisis dokumentasi. Ditemukan bahwa refleksi nilai pancasila pada budaya masyarakat Sumba terdapat pada ungkapan syair adat dan perilaku budaya marapu. Nilai-nilai Sila Pancasila yang terdapat dalam masyarakat adat Sumba dapat dijadikan sebagai sebuah pendekatan belajar berbasis etnopedagogi dalam pembelajaran Pendidikan Pancasila dan kewarganegaraan dan Pendidikan Ilmu Pengetahuan Sosial di Sekolah Dasar serta sebagai sarana pewarisan budaya lokal masyarakat Adat Sumba lewat pendidikan.
\end{abstract}

Kata Kunci: Nilai-nilai Pancasila; Kebudayaan Sumba; Etnopedagogi.

\begin{abstract}
Pancasila as the ideology of the Indonesian nation and the cause of materiality from Pancasila is culture. The culture of the indigenous people of Sumba is a wealth of Indonesian culture that supports the integrity of Pancasila. This paper is to answer several research questions as follows; How to reflect on the values of the one and only divine precepts in the local culture of the Sumba indigenous people? How to reflect on the values of populist precepts led by wisdom on the local culture of the indigenous peoples of Sumba, 5) How to reflect on the value of social justice for all Indonesian people in the local culture of the indigenous people of Sumba? Data were collected by conducting research with the phenomenological method, in which data were collected through interviews and documentation analysis. It was found that the reflection of the value of Pancasila in the culture of the people of Sumba was found in the expressions of traditional poetry and the behavior of the Marapu culture. The values of the Pancasila Precepts found in the indigenous peoples of Sumba can be used as an ethnopedagogical-based learning approach in learning Pancasila and civic education and social science education in elementary schools as well as a means of inheriting local culture of the Sumba Indigenous community through education.
\end{abstract}

Keywords: Pancasila Values; Sumba Culture; Ethnopedagogy. 


\section{PENDAHULUAN}

Bangsa Indonesia merupakan negara dengan wilayah kepulauan terbesar di dunia dan memiliki penduduk terbanyak keempat di dunia. Walaupun seperti itu, tidak membuat Indonesia menjadi negara yang terpecah belah. Alasannya adalah negara Indonesia mempunyai Ideologi yang kuat yaitu Pancasila (Febriansyah, D., dkk. 2018). Tilaar (2015) mentayatakan bahwa ideologi atau nilai yang terkandung dalam pancasila bersumber dari nilai-nilai yang dimiliki oleh bangsa Indonesia yang tumbuh dan berkembang di Indonesia yang terdapat di dalam adat-istiadat dan dalam agama-agama bangsa Indonesia. Pancasila dengan nilainilai yang tekandung didalamnya merupakan kristalisasi dari adat-istiadat, kebiasaan, sosial, kebudayaan serta agama-agama yang tumbuh dan berkembang di negara Indonesia. Dengan kata lain Pancasila lahir dari nilainilai kebudayaan suku bangsa Indonesia.

Kebudayaan merupakan salah satu anasir identitas manusia yang menempatkan manusia dalam kedudukan tertinggi di muka bumi. Manusia merupakan sentral dari kebudayaan, yang artinya manusia adalah pencipta kebudayaa, pemakai kebudayaan hingga mewariskan kebudayaan (Koentjaraningrat, 2009). Pasal 32 Undangundang Dasar tahun 1945 menjelaskan bahwa negara Indonesia mendukung kemajuan kebudayaan nasional Indonesia. Pemerintah secara langsung harus mengembangkan potensi yang ada, yang berkaitan dengan kebudayaan itu sendiri, sehingga memperkaya kebudayaan nasional Indonesia (Depdikbud, 1990:1). Kebudayaan Indonesia itu sendiri beraneka ragam jenis sesuai dengan persebaran pulau atau suku bangsa. Tujuan mengembangkan kebudayan dilatarbelakangi oleh kebutuhan untuk menempatkan kebudayaan nasional pada derajat yang tinggi atas dasar pemahaman bahwa kebudayaan nasional, yang menjamin unsur-unsur kebudayaan daerah, merupakan identitas bangsa dan negara yang harus dilestarikan, dikembangkan, dan diteguhkan di tengah perubahan global yang pesat dan dapat mengancam identitas bangsa dan negara Indonesia (Fanpula dalam Pingge, 2020).

Kebudayaan dalam konteks kebangsaan selalu berhubungan dengan identitas nasional. Oleh karena itu kebudayaan daerah merupakan kumpulan kebudayaan yang membentuk identitas bangsa Indonesia. Kebudayaan daerah mempunyai sifat dan nilai yang universal (Liliweri, 2014). Kebudayaan yang dimiliki oleh manusia yang membedakan dengan makluk hidup lainnya, sehingga manusia bukan saja sebagai makluk sosial tapi juga sebagai manusia atau makluk berbudaya (Lubis, M.2012).

Kebudayaan lokal masyarakat yang mendiami pulau Sumba tentunya mendukung kebudayaan nasional serta nilai-nilaii sila panca sila mewakili nilai budaya lokal ataupun sebaliknya. Masyarakat Sumba mendiami pulau Sumba yang terletak di barat daya Provinsi Nusa Tenggara Timur (NTT), sekitar 96 km disebelah selatan Pulau Flores $295 \mathrm{~km}$ disebelah barat daya Pulau Timor dan $1.125 \mathrm{~km}$ disebelah laut Darwin, Australia (Fredy dan Prapancha Hary dalam Pinggeroni \& Rahel 2020). Pulau Sumba terdiri dari empat kabupaten Sumba Timur,

Sumba Tengah, Sumba Barat dan Sumba Barat Daya pulau ini berada pada busur luar kepulauan Nusa Tenggara, dan pada busur tersebut Pulau Sumba terletak antara Pulau Sumbawa dan Pulau Timor. Masyarakat pulau Sumba masih ada yang menganut kepercayaan lokal yakni Marapu. Kepercayaan Marapu ini dianut oleh warga 
sejak jaman dahulu sebelum agama yang diakui di Indonesia masuk ke pulau Sumba. Marapu menganut paham animisme, yaitu pemujaan pada roh leluhur.

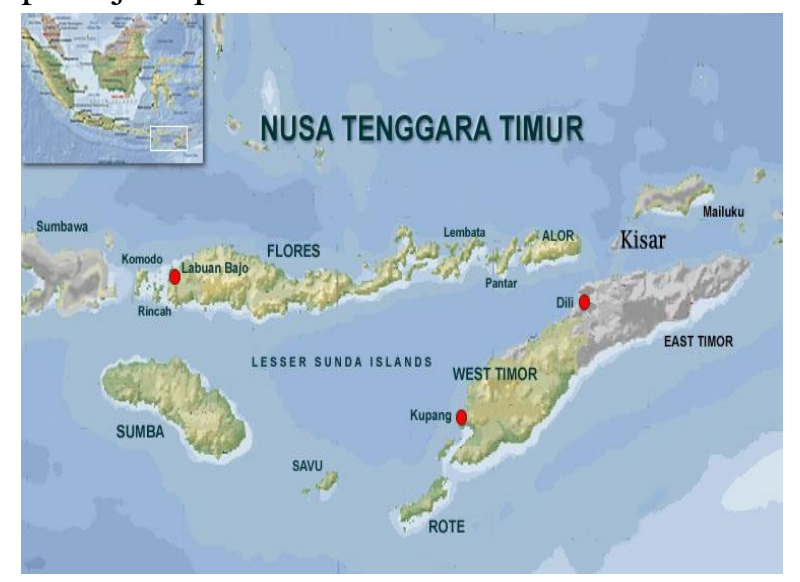

(Gambar dari: www.lavalontouristinfo.com)

Gambar 1. Pulau Sumba dalam Peta Propinsi Nusa Tenggara Timur

Pulau Sumba identik dengan marapu. Marapu merupakan sebuah kepercayaan pada Tuhan Yang Maha Esa (Solihin, 2009). Supaya mengenal Sumba hanya melalui Marapu. Ada keterkaitan antara hidup sosial dan sistem kepercayaan. Kepercayaan Marapu merupakan sebuah kepercayaan lokal masyarakat Sumba. Penganut kepercayaan marapu dalam KTP tercatat menganut agama yang diakui di Indonesia akan tetapi dalam keseharian hampir sebagian masyarakat Sumba masih menjalankan kepercayaan lokal. Tercatat pada kabupaten Sumba Timur ada 18.414 jiwa penganut kepercayaan marapu (www.tribunnews.com).

Para penganut marapu percaya akan kekuatan yang ada di luar dunia manusia yang masih mempengaruhi dan bahkan menentukan hidup mereka. Kekuatan itu adalah kekuatan dari para leluhur atau nenek moyang mereka. Oleh karena itu kepercayaan Marapu ini merupakan penyembahan kepada leluhur atau nenek moyang. Munculnya keyakinan akan adanya kekuatan-kekuatan gaib merupakan perwujudan dari kebutuhan manusia yang mencari keamanan, perlindungan dan ketenteraman (Fernandez dalam Pingge \& Rahel, 2020).

Pola hidup sosial budaya masyarakat sumba dipengarui oleh Marapu (Bobo Riti, 2015). Salah satu unsur penting dalam marapu adalah syair adat serta kegiatan adat istiadatan lainya. Syair adat kaya akan makna dan sebagai penggerak bagi masyarakat sumba dalam kehidupan. Syair adat merupakan sebuah seni dalam bertutur baik pada sesama maupun pada lelulur (Hudijono, 2009). Seni baca syair adat yang biasa dilakukan oleh seorang Rato (imam), yang mempunyai pengaruh sosial cukup tinggi, yang patut didengar dan dihormati oleh seluruh anggota masyarakat. Konsep tentang hidup bersama, tentang maha pencipta, saling membantu serta nilai kemanusiaan lainnya tertuang terdapat dalam adat kebiasaaan marapu.

Pancasila berdasarkan klasifikasinya terbagi menjadi tiga nilai yakni nilai dasar, nilai instrumental dan nilai praksis. Dalam usaha untuk melaksanakan nilai dasar maka dilaksanakan melalui nilai instrumental secara yuridis atau hukum dan untuk melaksanakan nilai dasar itu di dalam kehidupan yang nyata yaitu melalui nilai praksis Pancasila (Febriansyah, D., dkk. 2018). Nilai praksis menurut Setiadi, Elly M (2005) adalah nilai yang berlaku dan diimplementasikan dalam kehidupan yang sebenarnya dan merupakan perwujudan dari nilai instrumental dan nilai dasar. Nilai inilah pembuktian apakah nilai dasar dan nilai instrumental berlaku dalam kehidupan masyarakat. Dapat disimpulkan nilai praksis adalah perwujudan dari nilai instrumental dan nilai dasar Pancasila dalam kehidupan yang nyata. Sebagai pedoman praktis pengamalan dari kelima sila Pancasila di dalam kehidupan masyarakat secara lebih 
detail dijelaskan berdasarkan ketetetapan MPR Nomor: II/MPR/1978. (Munir dkk, 2016:151)

Berdasarkan pernyataan tersebut diperoleh kesimpulan bahwa ideologi bangsa Indonesia adalah Pancasila dan kausa materialitas dari Pancasila salah satunya adalah kebudayaan. Tentunya nilai-nilai panca sila yang mempersatukan dan sebagai ideologi bangsa Indonesia terdapat dan teresapi dalam segala bentuk kehidupan berbudaya masyarakat Sumba.

Atas dasar pimikiran diatas maka tulisan ini mengajukan rumusan masalah yaitu, 1) Bagaimana refleksi nilai sila ketuhanan yang maha esa pada budaya lokal masyarakat Sumba?, 2) Bagaimana refleksi nilai sila kemanusiaan yang adil dan beradab pada budaya lokal masyarakat Sumba, 3) Bagaimana refleksi nilai persatuan Indonesia pada budaya lokal masyarakat Sumba, 4) Bagaimana refleksi nilai sila kerakyatan yang dipimpin oleh hikmat kebijaksanaan pada budaya lokal masyarakat Sumba, 5) Bagaimana refleksi nilai keadilan sosial bagi seluruh rakyat Indonesiapada budaya lokal masyarakat Sumba?.

\section{METODE PENELITIAN}

Metode yang digunakan dalam penelitian adalah metode deskripsi kualitatif. Moleong (2012:6) menjelaskan bahwa "penelitian kualitatif bermaksud untuk memahami fenomena tentang apa yang dialami oleh subjek penelitian misalnya perilaku, persepsi, motivasi, tindakan dan lain-lain.”.

Penelitian dilakukan pada masyarakat adat Loura-Wewewa kabupaten Sumba Barat Daya, NTT, dimana data dikumpulkan melalui wawancara dan analisis dokumentasi. Teknik analisis data yang digunakan adalah teknik analisis interaktif yang dikemukakan oleh Miles dan Huberman (1992:16) yakni Pengumpulan data (data Collection), Reduksi data (data reduction), Sajian data (data display), dan Penarikan simpulan atau verifikasi

(Conclusion:drawing/Verification).

\section{HASIL DAN PEMBAHASAN}

Nilai Sila Ketuhanan Yang Maha Esa Pada Budaya Lokal Masyarakat Sumba

Nilai sila pertama pada budaya lokal masyarakat Sumba dapat dilihat dari keyakinan mereka lewat kepercayaan Marapu. Masyarakat Sumba percaya adanya Tuhan Yang Maha Esa yang sebagai pencipta dan juga percaya ada kehidupan setelah kematian. Hal tersebut dapat dilihat dalam syair adat dan prilaku budaya.

Syair adat yang mempresentasikan nilai sila pertama adalah "a kanga limma...a kanga wa'i".Syair adat tersebut bila diterjemahan secara lurus berarti "yang membagi jari tangan-yang membagi jari kaki". syair adat tersebut berarti bahwa masyarakat penganut Marapu percaya dan yakin bahwa ada maha pencipta yang membagi manusia dalam keberaneka ramam. Hal tersebut dapat dilhat bahwa masyarakat Sumba dapat hidup berdampingan walaupun berbeda suku atau klan. Syair adat tersebut merupakan bahasa Wewewa-Loura. Dipulau sumba terdapat delapan bahasa daerah yang berbeda. Penggungkapan syair adat berbeda secara bahasa tetapu meliki makna yang sama.

Sifat maha pencipta tersebut digambarkankan dalam ungkapan adat "a beleka katillu-a kalada mata" bila diterjemahkan secara lurus adalah "yang bertelinga lebar dan bermata besar". ungkapan tersebut mengambarkan sifat maha pecipta yang mampu melihat segala aktifitas manusia yang masih hidup dan yang sudah meninggal (roh) serta mampu mendengarkan 
keluh kesah dan syukur para umatnya. Karena maha pencipta dianggap sakral dan suci maka dijuluki lewat ungkapan "Ndappa tekki tamo, ndapa teki ngara". yang bermakna bawah Tuhan itu tidak bernama maka perlu menggunakan ungkapan atau syair yang cocok bila berkomunikasi padanya. Bentuk prilaku budaya yang berkaitan dengan sila pertama dapat dilihat pada tempat-tempat ritual Marapu. Ada tempat ritual seperti;

Marapu Wanno, Marapu Wanno merupakan tempat ritual yang ditempatkan ditengah kampung adat. Kampung adat di Sumba berbentuk huruf "U" atau "O" dan ditengah kampung merupakan ruang publik dan tempat marapu wanno. Marapu wanno berfungsi sebagai penjaga kampung. Pada marapu wanno diletakkan sirih pinang atau hasil panen dari kebun sebagai sarana komunikasi dan persembahan pada pelindung kampung.

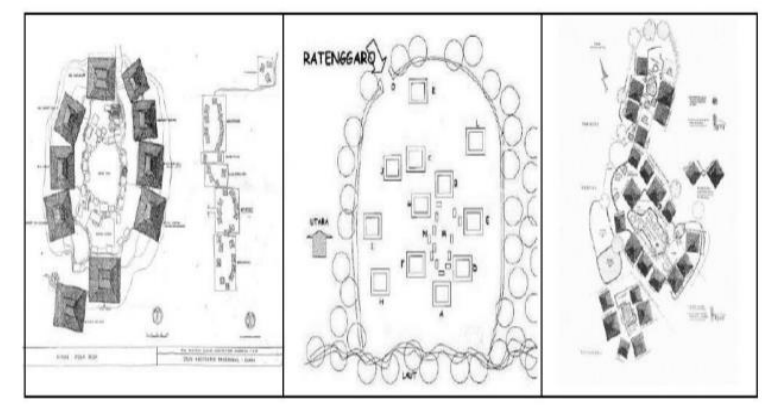

Gambar 2. Pola pemukiman kampung adat masyarakat Sumba (Harijanto, dkk. 2012)

Marapu oma. Merupakan roh pelingdung kebun atau sawah. Marapu oma ditempatkan pada ujung atau sudut kebun. Pada saat akan dikalukan penggarapan kebun dan panen dilakukan ritual pada marapu oma. Marapu oma diyakin sebagai pelingdung dari hama dan dapat memberikan panen yang melimpah

Marapu umma. Merupakan marapu atau roh yang melindungi masing-masing rumah. Marapu umpa ditempatkan disalah satu sudut rumah yang dianggap sakral. Marapu umma dianggap sebagai roh nenek moyang yang sudah meninggal. Ritual pada marapu umma dilakukan sesuai keperluan misalnya ritual bila ada anggota keluarga yang sakit, pada saat kematian, meminta berkat dan sebagainya.

Marapu tana. Merupakan marapu yang diyakini menjaga padang sabana sebagai tempat ternak, mata air, hutan dan gunung. Diyakini bawah padang, mata air dan hutan ada pelindung dan pengguninya. Maka ada larangan untuk merusak dan membakar hutan atau padang. Serta harus meminta ijin lewat ritual adat pada marapu tana bila menebang pohon untuk pembautan rumah atau keperluan lainnya.

\section{Nilai Sila Kemanusiaan Yang Adil Dan Beradab Pada Budaya Lokal Masyarakat Sumba}

Nilai sila kedua pancasila berkaitan dengan kemanusiaan, keadilan dan keberadaban singkatnya tentang humanisasi. Nilai sila ini dalam kebudayaan masyarakat Sumba terdapat dalam ungkapan syair adat yang mengambarkan tentang kedudukan manusia yang sederajat yakni "dede ole perateppe ole beika" perumpaan lainnya dapat dilihat dalam ajaran budaya lewat ungkapan "Dusebukan padoumadii oleh atamu" yang berarti "Kamu jangan merampas hak sesamu sesamamu, miliki atau menikmati apa yang menjadi hak kita.

Sedangkan dalam prilaku budaya dapat dilihat dari kegiatan sehari-hari seperti semua anggota keluarga ataupun tamu menikmati makanan dari tempat masak atau "wirro" yang sama, tidak ada pelayanan khusus. Sama halnya dalam kegiatan pertemuan adat istiadat semua yang hadir dipersilakan untuk menyampaikan pendapat.

Nilai Persatuan Indonesia Pada Budaya 


\section{Lokal Masyarakat Sumba}

Nilai sila ketiga pancasila dapat dilihat pada syair adat yang menggambarkan dan mengajak semua umat manusia di Sumba untuk bersatu dan menjaga keutuhan yakni "Maliti yapa bewa, kadoke yapangago" yang bila diartikan secara lurus "Beringin yang rimbun dengan pohonnya yang besar. Sedangkan dalam prilaku budaya dapat dilihat dari ikatan suku atau marga yang masih sangat kuat, dimana semua orang sumba selalu melakukan kegiatan adat istiadat bersama diruma besar. Rumah besar orang sumba menandakan asal nenek moyang. Setiap suku di sumba memiliki rumah besar, contohnya di Loura kabupaten Sumba Barat Daya, Rumah besar suku-suku orang Loura berada di Desa Karuni, Wanno Karedi.

Secara ekonomi pendapat masyarakat Sumba dibawah rata-rata, untuk melakukan kegiatan yang membutuhkan biaya banyak seperti membangun rumah atau proses pembelisan tentulah tidak dapat terwujud. Namun lewat kegiatan "kumpul tangan" biaya yang besar dapat teratasi. Kegiatan kumpul tangan bentuknya seperti arisan. Belis atau mahar kawin di Sumba dalam bentuk ternak besar (kerbau, kuda dan babi) dalam jumlah puluhan ekor.

\section{Nilai Sila Kerakyatan Yang Dipimpin Oleh Hikmat Kebijaksanaan Pada Budaya Lokal Masyarakat Sumba}

Nilai sila keempat pancasila dalam kebudayaan masyarakat sumba tercermin dalam kepemimpinan Rato adat. Rato adat mempunyai peran yang sangat penting dalam kehidupan bermasyarakat. Rato merupakan pemimpin adat atau Imam Marapu yang mempunyai kedudukan yang penting dalam masyarakat. Berperan sebagai mediator dan menyelesaikan konflik. Rato adat juga sebagai imam marapu, mimimpin setiap ritual adat, sebagai perantara antara roh yang sudah meninggal dengan keluarga yang masih hidup. Pesan leluhur yang disampaikan lewat rato adat harus dapat dijalankan oleh manusia yang masih hidup. Setiap suku atau klan mempunyai rato adat sendiri. Rato adat setiap suku berkedudukan di uma kalada.

\section{Nilai Keadilan Sosial Bagi Seluruh Rakyat Indonesia pada Budaya Lokal Masyarakat Sumba}

Nilai sila kelima pada budaya masyarakat Sumba dapat dilhat pada prilaku budaya dalam pemanfaatan ruang public kampung adat. Setiap rumah suku yang terdapat dalam kampung adat dapat menggunakan ruang publik tersebut. Disamping itu nilai keadilan sosial tercermin dalam keputusan rato adat dalam mneyelesaikan konflik yang terjadi. Tidak ada pihak yang dirugikan dan pihak yang diuntungkan. Saling membalas rappo juga merupakan tindakan adil dalam membalas jasa.

Temuan diatas menggambarkan sejarah Indonesoan bahwa sejak awal pendiriannya, Indonesia adalah bangsa yang menampung ideologi-ideologi tradisional. Kesemuanya itu dipertemukan dengan kearifan lokal, diambil intisarinya, dan direproduksi menjadi Pancasila. Nilai-nilai Pancasila tersebut perlu dipahami dengan baik oleh siswa disekolah dasar dengan memanfaatkan kearifan lokal. Pemanfaatan kearifan lokal dalam pendidikan dikenal dengan pendekatan etnopedagogi. Etnopedagogi adalah suatu pendekatan belajar yang memanfaatkan budaya sebagai sumber belajar (Alwasilah, dkk, 2009: Dunbar-Hal, 2009; Oktavianti dan Ratnasari, 2018)

Pendekatan etnopedagogi dalam mengajarkan nilai-nilai sila pancasila berbasis budaya Sumba dapat di intergasikan 
dalam mata pelajaran pendidikan pancasila dan kewarganegaraan dan pendidikan Ilmu pengetahuan sosial. Kedua mata pelajaran tersebut dalam kajian standar isinya membicarkan pancasila sebagai ideologi negara, sejarah pancasila, nilai-nilai pancasila serta penerapan nilai sila pancasila.

\section{KESIMPULAN}

Pancasila merupakan landasan bangsa Indonesia yang mempersatukan keutuhan bangsa. Nilai-nilai yang tertuang dalam sila pancasila merupakan cerminan budaya suku bangsa. Masyarakat yang mendiami pulau Sumba sangat kaya akan budaya lokal yang unik. Kebudayaan masyarakat Sumba bila direfleksikan dengan nilai-nilai sila pancasila tercermin dalam ungkapan syair adat dan prilaku budaya Marapu.

Nilai sila pancasila tersebut yang terdapat dalam budaya Marapu masyarakat adat Sumba dapat diangkat sebagai sumber belajar dengan menggunakan pendekatan etnopedagogi. Dengan pendekatan ini siswa dengan mudah memahami pancasila dari perspektif budaya dan sekaligus mepelajari dan mempertankan kebudayaan.

\section{DAFTAR RUJUKAN}

Arif, D. (2014). Pengaruh Penggunaan Media Kartu terhadap Kemampuan Membaca Siswa Kelas I SDN 10 Lubuk Buaya Padang. Jurnal Al-Ta'lim.

Alwasilah, A. C.dkk 2009. Etnopedagogi: Landasan praktek pendidikan dan pendidikan guru. Kiblat Buku Utama, Bandung.

Depdikbud, 1990. Sistem Pendidikan Nasional. Semarang: Media Wiyata.

Febriansyah, D., dkk. (2018). Analisis Nilai-Nilai Pancasila Yang Terkandung Di Dalam Seni Tutur Tadut (Studi Kasus Tadut Di Kota Pagaralam). Jurnal Bhinneka Tunggal Ika,5(1) Pp 35-51.

Harijanto, Agus Dwi, dkk (2012) Hubungan
Ruang, Bentuk dan makna pada arsitektur tradisonal sumba barat: Universtitas Petra Laporan penelitian tidak dipublikasikan.

Hudijono. 2009. Syair-Syair Adat Dalam Budaya Penyelesaian Sengketa Di Sumba Barat: Dunia Seni Dalam Realitas Spiritual. Kajian Linguistik dan Sastra. 21, (2). pp.113-122.

Koentjaraningrat. 2009/ Pengatar Ilmu Antropologi (edisi Revisi. Jakarta: Rineka Cipta.

Liliweri, A. 2014. Pengantar Studi kebudayaan. Bandung: Nusa Media.

Lubis, M.(2012). Transformasi Budaya untuk Masa Depan. Jakarta: Gunung Agung.

Oktavianti dan Ratnasari.2018.Etnopedagogi Dalam Pembelajaran Di Sekolah Dasar Melalui Media Berbasis Kearifan Lokal. Jurnal Refleksi Edukatika 8 (2). pp. 149154.

Pingge, H.D. (2019). Learning materials based on local wisdom of Sumbanese as the source of learning in elementary school. Proceedings the 4th International Seminar on Social Studies and History Education (ISSSHE). Bandung: UPI.

Pingge, H.D \& Rahel H (2020). Kain Tenun Ikat Sebagai Media Pembelajaran IPS Di Sekolah Dasar . JIPSINDO.7(1) pp 22-43.

Setiadi, Elly M. (2005). Pendidikan Pancasila Untuk Perguruan Tinggi. Jakarta: PT Gramedia Pustaka Utama.

Solihin. 2009. The Marapu Belief: Divine Concept and the Sumbanese's View on Ancestors. Tersedia Online.

Tilaar, H.A.R. 2015. Pedagogik Teoritis untuk Indonesia. Jakarta: $\mathrm{Pt}$ Kompas Media Nusantara.

Munir, dkk. (2016). Pendidikan Pancasila. Malang: Madani Media.

Miles, B. M dan Huberman. M. (1992). Analisis Data Kualitatif Buku Sumber Tentang Metode-metode Baru. Jakarta: UIP.

www.tribunnews.com (Selasa, 6 Maret 2018). Penganut Aliran Kepercayaan di Sumba Timur Mencapai 18.414 Jiwa dari https://www.tribunnews.com/regional/2018/ 03/06/penganut-aliran-kepercayaan-disumba-timur-mencapai-18414-jiwa www.lavalontouristinfo.com 